\title{
Impaired Renal Function is Associated with Severe Coronary Artery Disease in Chronic Stable Angina Patients
}

\author{
JN Saha, AAS Majumder, NA Chowdhury, M Ullah, MG Azam, KK Karmoker, MJ Islam, PR Das, MS \\ Islam, M Mamunuzzaman, P Biswas, MA Rahman \\ Department of Cardiology, National Institute of Cardiovascular Diseases, Dhaka, Bangladesh
}

\begin{abstract}
:
Key words:

Renal

Background: Cardiovascular disease is the leading cause of morbidity and mortality in renal impaired

Impairment, Coronary Artery patients. Many of the patients of chronic kidney disease die of cardiovascular disease before requiring dialysis. Cardiovascular disease in renal impaired patient is potentially preventable and treatable. The aim of this study was to evaluate the association between renal impairment and coronary artery disease severity in chronic stable angina patients.
\end{abstract}

Disease.

\begin{abstract}
Methods: 110 patients with chronic stable angina who got admitted for coronary angiography were included in the study. They were divided into impaired renal function group (with estimated glomerular filtration rate $\left.[e G F R]<90 \mathrm{ml} / \mathrm{min} / 1.73 \mathrm{~m}^{2}\right)$ and normal renal function group (eGFR e" $\left.90 \mathrm{ml} / \mathrm{min} / 1.73 \mathrm{~m}^{2}\right)$ on the basis of eGFR. The severity of the CAD was assessed by angiographic Vessel score and Gensini score.

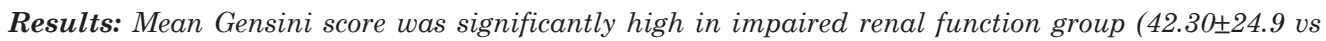
$25.65 \pm 17.9, p<0.05)$. There was significant negative correlation between eGFR and vessel score $(r=-0.30, p$ $<0.05)$ and between eGFR and Gensini score $(r=0.65, P<0.05)$. In multivariate logistic regression analysis, after adjustment of factors eGFR remain independent predictors of severe $C A D(P=0.002,0 R-5.73)$.

Conclusion: Impaired renal function, assessed by eGFR is associated with angiographic severe coronary artery disease in chronic stable angina patients and this association is independent of conventional cardiovascular risk factors.
\end{abstract}

(Cardiovasc. j. 2014; 7(1): 17-23)

\section{Introduction:}

Cardiovascular diseases (CVD) are the number one cause of death globally. An estimated 17.3 million people died from CVDs in 2008, representing $30 \%$ of all global deaths. Of these deaths, an estimated 7.3 million were due to coronary heart disease. The number of people who die from CVDs will increase to reach 23.3 million by 2030. Coronary artery disease (CAD) is the most common cause of CVD mortality. ${ }^{1}$ Cardiovascular diseases are becoming a significant burden on health care services in Bangladesh. ${ }^{2}$ With the increase incidence of DM and hypertension, the prevalence of CKD is also alarmingly going up. CKD is strongly associated with accelerated CVDs and this association is independent of conventional risk factors such as DM, hypertension, dyslpidaemia ${ }^{3}$ and caused by non-conventional risk factors such as anaemia, altered calcium- phosphorus metabolism, increased homocysteine level, inflammation and oxidative stress. ${ }^{4}$

The glomerular filtration rate (GFR), determined by the Cockcroft- Gault equation, is a more precise and accurate way of estimating kidney function than measuring serum creatinine. ${ }^{5}$ The United States National Kidney Foundation uses GFR rather than serum creatinine level to define renal dysfunction. National Kidney Foundation recommended estimated GFR for use in recognition, treatment and prevention of chronic kidney disease. It is considered as the overall best indicator of kidney function. Serum creatinine alone fails to identify many patients whose kidney function is reduced. For example, an elderly person could lose half of their kidney function before serum creatinine rises above the normal level. ${ }^{6}$ 
Renal function is an important predictor of the presence and severity of angiographic CAD even in patients without severe renal impairment. ${ }^{7}$ Early stages of CKD that are characterized by relatively preserved renal function are associated with increasing incidence of de novo and recurrent CVD events. ${ }^{8}$ As GFR diminishes the prevalence and severity of CAD increases ${ }^{9}$. Patients with CKD have more severe CAD that's why there is a high rate of cardiovascular events in CKD patients. ${ }^{10}$ CVD is the main cause of morbidity and mortality in renal impaired patient. Individuals with CKD are more likely to die of CVD than to develop end-stage renal disease. ${ }^{11}$ CVD in renal impaired patients is potentially preventable and treatable.

\section{Materials and methods:}

Study population

110 patients of chronic stable angina who got admitted for coronary angiogram into department of cardiology, NICVD from January to October 2013, were selected by purposive sampling for this analytical study. The main objective of the study was to find out the association between impaired renal function and coronary artery disease severity in patients with chronic stable angina. Patients with DM, Cardiomyopathy, Valvular or Congenital heart disease, left ventricular ejection fraction $<40 \%$, or prior history of PCI/CABG were excluded from the study. They were divided into two groups on the basis of renal function; group I $(n=55)$ : impaired renal function group (eGFR $<90 \mathrm{ml} /$ $\left.\mathrm{min} / 1.73 \mathrm{~m}^{2}\right)$ and group II ( $\left.=55\right)$ : normal renal function group (eGFR $\geq 90 \mathrm{ml} / \mathrm{min} / 1.73 \mathrm{~m}^{2}$ ).

Assessment of renal function:

Estimated glomerular filtration rate (eGFR) was used for the evaluation of renal functional status and calculated by the Cockroft \& Gault formula:

$$
\text { eGFR }=\frac{140-\text { age }[\text { years }] \mathrm{x} \text { weight }[\mathrm{in} \mathrm{kg}]}{\text { serum creatinine }[\mathrm{mg} / \mathrm{dl}] \mathrm{x} 72}
$$

(For female patients, obtained value was multiplied by 0.85 )

Coronary angiogram and determination of the severity of CAD:

Coronary angiogram was done after appropriate patient preparation. Nephrotoxic drugs
(eg.NSAIDs) were stopped and hydration with intravenous normal saline was done to prevent contrast induced nephropathy in high risk patients. All angiography were evaluated by two experienced cardiologists who were blinded to the study. The severity of the CAD was assessed by Vessel score and Gensini score.

Vessel score: This is the number of vessel with a significant stenosis (for left main coronary artery $50 \%$ or greater and for others $70 \%$ or greater reduction in luminal diameter. coronary artery stenosis $<70 \%$ in major epicardial coronary arteries were termed non-obstructive CAD). ${ }^{12}$ Score ranges from 0 to 3 , depending on the number of vessel involved. Left main coronary artery will be scored as single vessel disease. ${ }^{13}$

Score $0=$ no vessel involvement/non obstructive CAD.

Score 1 = single vessel involvement.

Score 2 = double vessel involvement.

Score 3 = triple vessel involvement

Gensini score: The Gensini score was developed by Gensini and takes into consideration the geometrical severity of lesions by angiography, the cumulative effects of multiple obstructions and the significance of jeopardized myocardium. A nonlinear score is assigned to each lesion based on the severity of stenosis as indicated by the reduction of lumen diameter. A multiplier is applied to each lesion score based upon its location in the coronary tree depending on the functional significance of the area supplied by that segment. The final Gensini score is the sum of the lesion scores. ${ }^{14}$ According to Gensini score CAD is categorized as mild (1-10), moderate (11-50) and severe $(>50) .{ }^{15}$

\section{Statistical methods:}

The numerical data obtained from the study were analyzed and significance of differences were estimated by using statistical methods. The SPSS Statistical Software (16.0 version, SPSS Inc., Chicago, Illinois, USA) was used for data analysis. Continuous variables were expressed in mean \& standard deviation and categorical variables as frequency and percentage. Quantitative variables were analyzed by Student's t-test and ANOVA and Categorical 
Impaired Renal Function is Associated with Severe Coronary Artery

JN Saha et al.

\begin{tabular}{lc}
\hline \multicolumn{1}{c}{ Gensini score } & \\
Segment & Weighting factor \\
\hline Proximal RCA & 1.0 \\
Mid-RCA & 1.0 \\
Distal RCA & 1.0 \\
Posterior descending branch & 1.0 \\
Left posterior ventricular branch & 1.0 \\
LM coronary artery & 5.0 \\
Proximal left anterior descending & 2.5 \\
Mid-left anterior descending & 1.5 \\
Distal left anterior descending & 1.0 \\
First diagonal branch & 1.0 \\
Second diagonal branch & 0.5 \\
Proximal LCX & 2.5 \\
Distal LCX & 1.0 \\
Obtuse marginal & 1.0 \\
\hline
\end{tabular}

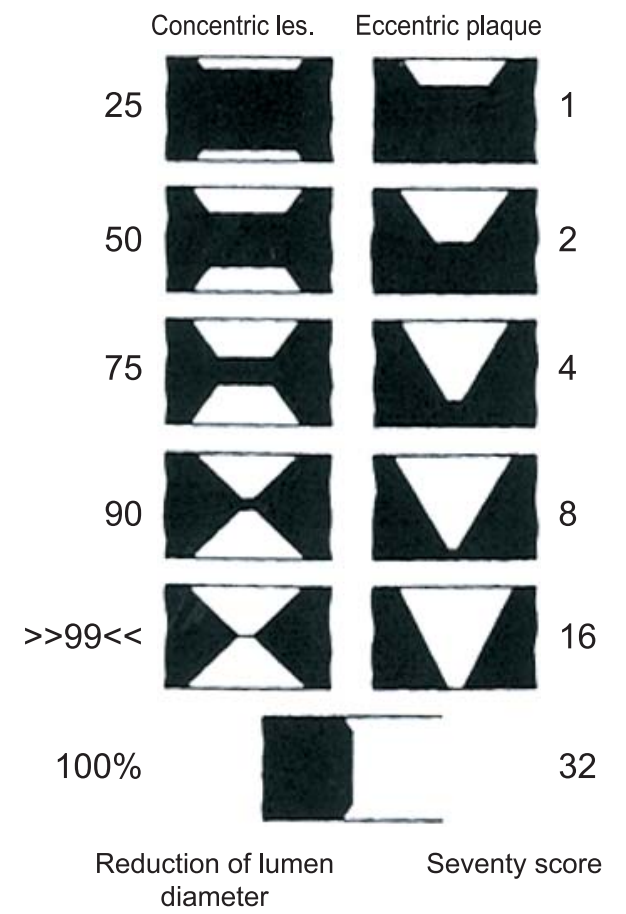

Fig.-1: Gensini Score: Left panel- weighting factor according to the importance of vessel in the coronary tree ${ }^{16}$ Right panel-severity score according to reduction of lumen diameter. ${ }^{17}$

variables were analyzed by chi-square test and Fisher's exact test as applicable. To test association between impaired renal function and coronary artery disease severity pearson's and Spearman's rank order correlation test used. Univariate and multivariate logistic regression analysis were done to evaluate the independent predictors of severe CAD. The odds ratio (OR) and $95 \%$ confidence interval were calculated. $p$ value of less than 0.05 was considered as significant.

\section{Results:}

The mean age of patients of group-I is 55.60 and group-ÉÉ is 49.40 years and the difference is statistically significant. Male:Female ratio is 10:1. BMI is significantly low in group-É. Among the conventional CVD risk factors, hypertension and dyslipidaemia are significantly high in group-É. No significant difference between two groups was found in case of smoking and family history of CAD. Study groups were well matched in terms of drug history (Table-I)

Table-I

Demographic and clinical factors of study patients $(n=110)$

\begin{tabular}{|c|c|c|c|}
\hline Variables & $\begin{array}{l}\text { Impaired renal function } \\
\text { group I }(\mathrm{n}=55)\end{array}$ & $\begin{array}{l}\text { Normal renal function } \\
\text { group II }(\mathrm{n}=55)\end{array}$ & $\mathrm{p}$ value \\
\hline Age, mean $\pm \mathrm{SD}$, years & $55.60 \pm 7.5$ & $49.40 \pm 6.6$ & 0.001 \\
\hline Sex, male: female & 10:1 & 10:1 & 1.0 \\
\hline $\mathrm{BMI}$, mean $\pm \mathrm{SD}, \mathrm{kg} / \mathrm{m} 2$ & $22.70 \pm 1.2$ & $24.1 \pm 2.1$ & 0.001 \\
\hline Hypertension, n (\%) & $25(45.5)$ & $14(25.5)$ & 0.03 \\
\hline Dyslipidaemia, n (\%) & $19(34.5)$ & $9(16.4)$ & 0.03 \\
\hline Smoking, n (\%) & $18(32.7)$ & $16(29.1)$ & 0.68 \\
\hline Family history of CAD, $\mathrm{n}(\%)$ & $6(10.9)$ & $4(7.3)$ & 0.74 \\
\hline \multicolumn{4}{|l|}{ Drug history } \\
\hline Antiplatelet, n (\%) & $50(90.90 \%)$ & $45(81.80 \%)$ & 0.16 \\
\hline Nitrates, n (\%) & $35(63.60 \%)$ & $43(78.20 \%)$ & 0.09 \\
\hline Beta blocker, n (\%) & $33(60.00 \%)$ & $33(60.00 \%)$ & 1.00 \\
\hline ACE Inhibitors, n (\%) & $18(32.70 \%)$ & $20(36.40 \%)$ & 0.68 \\
\hline Statins, n (\%) & $32(58.20 \%)$ & $30(54.50 \%)$ & 0.70 \\
\hline
\end{tabular}


The differences in mean haemoglobin and random blood sugar (RBS) level between two groups were insignificant. In lipid profile only TG was significantly high in group-I. The mean serum creatinine level was $1.34 \pm 0.3 \mathrm{mg} / \mathrm{dl}$ in group-I \& $0.80 \pm 0.1 \mathrm{mg} / \mathrm{dl}$ in group-II and the difference was statistically significant $(p=0.001)$. The mean eGFR in group-I and group-II were $60.70 \pm 12.60$ and $100.40 \pm 8.4 \mathrm{ml} / \mathrm{min} / 1.73 \mathrm{~m}^{2}$ respectively and the difference was significant.Mean LVEF is $49.60 \& 55.30 \%$ in group-I and group-II respectively with a significant difference between two group (Table-II).

CAD was mild in $9.1 \%$ patients in group I and $23.6 \%$ patients in group II and mild CAD was significantly low in group I $(p=0.04)$. Moderate CAD was found in $60 \%$ and $69.1 \%$ patients in group I and group II respectively with insignificant difference $(p=0.31)$. Severe CAD was found in $30.9 \%$ patients in group I and $7.3 \%$ patients in group II and was significantly higher in group I ( $\mathrm{p}=0.001)$ (Table-III).

\section{Table-II}

Laboratory characters of study patients $(n=110)$

\begin{tabular}{lccc}
\hline Variables & $\begin{array}{c}\text { Impaired renal function } \\
\text { group I }(\mathrm{n}=55)\end{array}$ & $\begin{array}{c}\text { Normal renal function } \\
\text { group II }(\mathrm{n}=55)\end{array}$ & $\mathrm{p}$ value \\
\hline Hb, mean $\pm \mathrm{SD},(\mathrm{gm} / \mathrm{dl})$ & $12.30 \pm 0.60$ & $13.90 \pm 1.20$ & 0.64 \\
RBS $(\mathrm{mg} / \mathrm{dl}) \quad 5.9 \pm 0.4$ & $5.9 \pm 0.4$ & 1.00 & \\
Lipid profile (mg/dl) & & & 0.08 \\
Total cholesterol & $171.10 \pm 13.30$ & $169.10 \pm 10.50$ & 0.09 \\
$\quad$ LDL & $120.60 \pm 12.90$ & $114.50 \pm 15.20$ & 0.44 \\
HDL & $36.20 \pm 3.60$ & $39.0 \pm 2.60$ & 0.005 \\
S. Triglyceride & $143.60 \pm 18.80$ & $133.70 \pm 16.90$ & 0.001 \\
Serum creatinine $(\mathrm{mg} / \mathrm{dl})$ & $1.34 \pm 0.30$ & $0.80 \pm 0.10$ & 0.001 \\
eGFR, $\left(\mathrm{ml} /\right.$ min $\left./ 1.73 \mathrm{~m}^{2}\right)$ & $60.70 \pm 12.60$ & $100.40 \pm 8.4$ & 0.02 \\
LVEF,mean $\pm \mathrm{SD},(\%)$ & $49.60 \pm 7.30$ & $53.30 \pm 8.50$ &
\end{tabular}

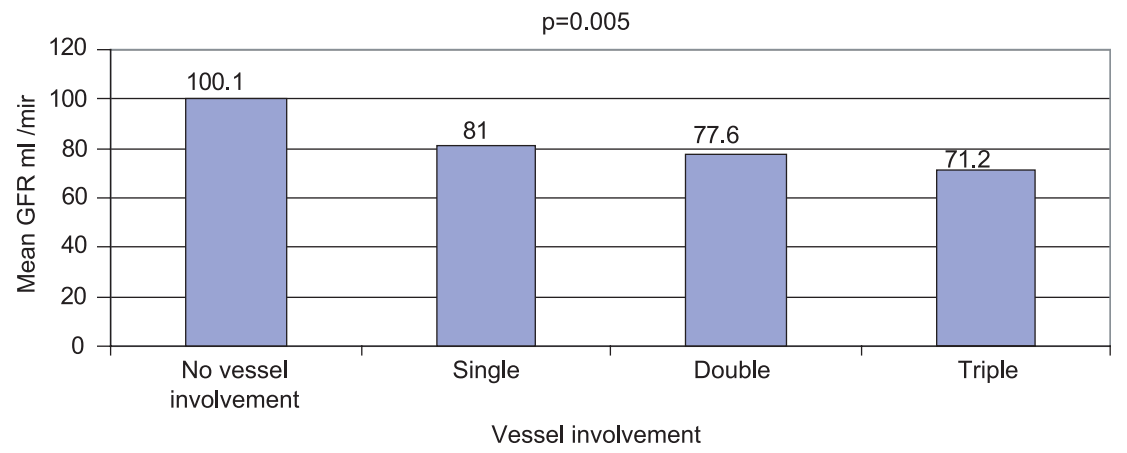

Fig-2: Bar diagram showing significant association between mean eGFR and vessel score.

Table-III

Distribution of the study patients according to Gensini score $(n=110)$

\begin{tabular}{|c|c|c|c|c|c|}
\hline \multirow[t]{2}{*}{$\begin{array}{l}\text { Severity of CAD } \\
\text { (Gensini score) }\end{array}$} & \multicolumn{2}{|c|}{$\begin{array}{l}\text { Impaired renal function } \\
\text { group I }(\mathrm{n}=55)\end{array}$} & \multicolumn{2}{|c|}{$\begin{array}{l}\text { Normal renal function } \\
\text { group II }(\mathrm{n}=55)\end{array}$} & \multirow[t]{2}{*}{$\begin{array}{c}\mathrm{p} \\
\text { value }\end{array}$} \\
\hline & Number & $\%$ & Number & $\%$ & \\
\hline Mild (1-10) & 5 & 9.1 & 13 & 23.6 & $0.04^{\mathrm{s}}$ \\
\hline Moderate $(10-50)$ & 33 & 60.0 & 38 & 69.1 & $0.31^{\mathrm{ns}}$ \\
\hline Severe $(>50)$ & 17 & 30.9 & 4 & 7.3 & $0.001^{\mathrm{s}}$ \\
\hline
\end{tabular}


In our study univariate logistic regression analysis of variables likely to cause severe $\mathrm{CAD}$ revealed that age $>45$ years $(\mathrm{P}=0.03)$, hypertension $(\mathrm{P}=0.007)$, dyslipidaemia $(\mathrm{P}=0.004)$, serum creatinine $(\mathrm{P}=0.002)$ and eGFR $(\mathrm{p}=0.003)$ were independent predictor of severe coronary artery disease with odds ratio (OR) being 1.88 , $3.93,5.01,5.54$ and 5.70 respectively.

In multivariate logistic regression analysis, after adjustment of factors, Hypertension, dyslipidemia, Serum creatinine and eGFR were found the independent predictors of severe CAD with ORs being $3.71,4.95,5.36$ and 5.73 respectively.

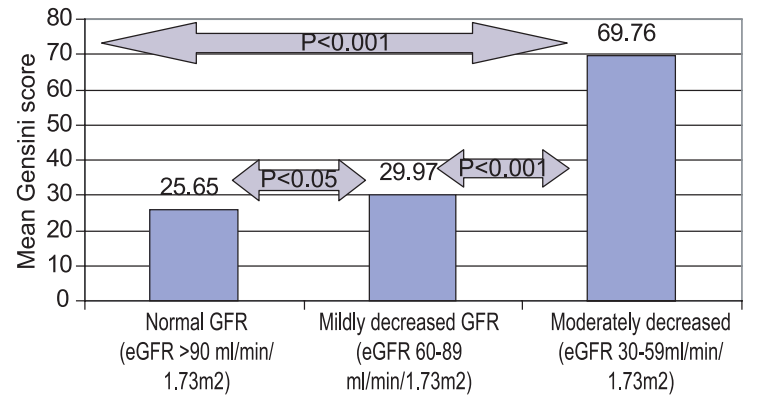

Fig-3: Mean Gensini score in different study group

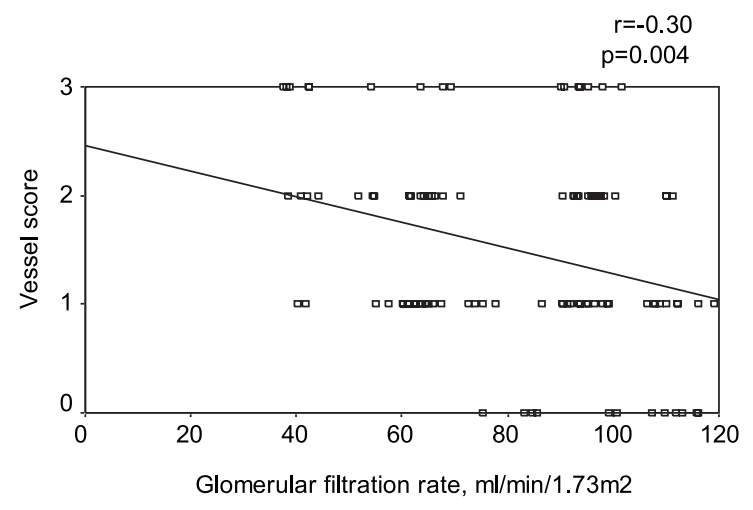

Fig-4: Statistically significant negative correlation between eGFR and Vessel score

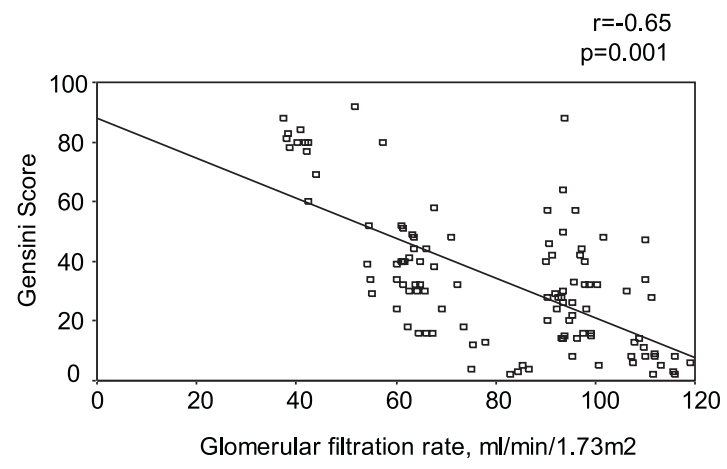

Fig-5: Statistically significant negative correlation between eGFR and Gensini score

\section{Discussion:}

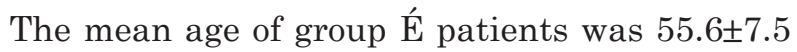
years and that of group ÉÉ was $49.4 \pm 6.6$ years $(\mathrm{p}<0.05)$. In a similar study mean age was $67.8 \pm$ 9.0 years in impaired renal function group and $52.5 \pm 10.3$ years in normal renal function group and difference was statistically significant ( $\mathrm{p}$ $<0.001) .{ }^{18}$ It was evident from the study that patients with renal impairment tended to be older than those with normal renal function. Chronic kidney disease (CKD) is a growing public health concern that overwhelmingly affects older adults.

Body mass index of patients of group I and group II were $22.7 \pm 1.2 \mathrm{~kg} / \mathrm{m}^{2}$ and $24.1 \pm 2.1 \mathrm{~kg} / \mathrm{m}^{2}$ respectively and difference was statistically significant $(\mathrm{P}<0.05)$. This was consistent with the findings that patients with CKD had lower body mass index levels than those with normal renal function $\left(23.5 \pm 0.2 \mathrm{~kg} / \mathrm{m}^{2}\right.$ vs. $24.0 \pm .02 \mathrm{~kg} /$ $\left.\mathrm{m}^{2}\right) .{ }^{9}$ It might indicate malnutrition due to low protein diet, uremic toxicity and inflammation in patients with renal impairment. Among the conventional risk factors of $\mathrm{CAD}$, diabetic patients were excluded from study; smoking \& family history of CAD were found non-significant but hypertension \& dyslipidaemia were significantly high in impaired renal function group. Though dyslipidaemia was found statistically significant in risk factor analysis, here lipoproteins level were well controlled which might be due to lipid lowering therapy with statin.

In our study the mean serum creatinine was $1.34 \pm 0.3 \mathrm{mg} / \mathrm{dl}$ in group É and $0.8 \pm 0.1 \mathrm{mg} / \mathrm{dl}$ in group II and the difference was statistically significant $(\mathrm{P}<0.05)$. In a similar study ${ }^{18}$ mean serum creatinine was $1.47 \pm 0.91$ in decreased renal function group and $0.87 \pm 0.17$ in patients with normal renal function. In comparison with our study, mean serum creatinine was high in decreased GFR group which might be explained as they included patients with end-stage renal disease but we didn't.

The mean eGFR of subjects with insignificant coronary artery disease was $100.1 \pm 14.5 \mathrm{ml} / \mathrm{min} /$ $1.73 \mathrm{~m}^{2}$ and that of single, double and triple vessel disease were $81 \pm 21.3,77.6 \pm 22.3$ and $71.2 \pm 24.7$ $\mathrm{ml} / \mathrm{min} / 1.73 \mathrm{~m}^{2}$ respectively. So, the mean eGFR 
decreased along with the increase in number of involved vessels $(\mathrm{p}<0.05)$. Mean Gensini score was $42.3 \pm 24.9$ and $25.65 \pm 17.9$ in group-I and group-II respectively and the difference of mean Gensini score was statistically significant $(p<0.05)$. In a related study ${ }^{18}$ mean Gensini score was $35 \pm 33$ in decreased renal function group and $13 \pm 16$ in normal kidney function group and the difference was statistically significant $(p<0.05)$. So our findings are consistent with existing studies. Among the impaired renal function patients mean Gensini score was significantly higher in moderately decreased GFR subgroup than mildly decreased GFR subgroup $(69.76 \pm 19.6$ vs $29.97 \pm 15.5$, $\mathrm{p}<0.05)$.

In our study correlation co-efficient between eGFR and vessel score was $r=-0.30(p<0.05)$ and correlation co-efficient between eGFR and Gensini score was $\mathrm{r}=-0.65(\mathrm{p}<0.05)$. In a similar study $^{18}$ the significant relationship between estimated GFR and Gensini score was reported $(\mathrm{r}=0.326, \mathrm{p}<0.05)$. We found a moderate negative correlation between eGFR and coronary artery disease severity in terms of Gensini score. With the decrease of GFR and so renal function, vessel score and Gensini score were increased, indicating more severe coronary artery disease.

Univariate logistic regression analysis of variables likely to cause severe $\mathrm{CAD}$ revealed that age $>45$ years $(\mathrm{P}<0.05)$, hypertension $(\mathrm{P}<0.05)$, dyslipidaemia $(\mathrm{P}<0.05)$, serum creatinine $(\mathrm{P}<0.05)$ and eGFR $(p<0.05)$ were independent predictor of severe coronary artery disease with odds ratio (OR) being $1.88,3.93,5.01,5.54$ and 5.70 respectively. However, smoking ( $p>0.05)$, BMI $(\mathrm{P}>0.05)$ and positive family history of premature $\mathrm{CAD}(\mathrm{p}>0.05)$ were not independent predictor of severe CAD. In multivariate logistic regression analysis, after adjustment of factors, Hypertension, dyslipidemia, Serum creatinine and eGFR were found the independent predictors of severe CAD with ORs being 3.71, 4.95, 5.36 and 5.73 respectively.

\section{Conclusion:}

From this study it may be concluded that impaired renal function assessed by estimated GFR is associated with angiographic severe coronary artery disease in patients with chronic stable angina and this association is independent of conventional cardiovascular risk factors.

\section{Study limitations:}

Although the result of this study supports the hypothesis, there are some facts to be considered which might affect the results.

1. Though adequate number of study population was included in our study, we believe that it is still limited in number to generalize the results and it was conducted in a single centre.

2. Sampling method was not random rather purposive, so there is risk of selection bias.

3. To assess renal function we have used eGFR, calculated from single measurement of serum creatinine instead of direct measurement which may give some weakness to our data. However, eGFR is widely accepted and an available marker in clinical practice and has a very important role in large epidemiologic studies whenever GFR measurement is not feasible for practical and cost-containing reasons.

\section{Conflict of Interest - None.}

\section{References:}

1. World Health Organization, 2013, Cardiovascular disease.(pdf). Available at: (www.who.int/mediacentre/ factsheets/fs317/en/).[Accessed date 23 October, 2013]

2. Islam MN, Ali MA, Ali M. Spectrum of Cardiovascular Disease: The current scenario in Bangladesh. Bangladesh Heart Journal 2004; 19:1-7.

3. Sarnak MJ, Levey AS, Schoolwerth AC, et al. Kidney disease as a risk factor for development of cardiovascular disease: a statement from the American Heart Association Councils on Kidney inCardiovascular Disease, High Blood Pressure Research, Clinical Cardiology and Epidemiology and Prevention. Hypertension 2003; 42(5): 1050-1065.

4. Bhatt DL. Anti-inflammatory agents and antioxidants as a possible 'third great wave' in cardiovascular secondary prevention. Am J Cardiol 2008; 101: 4-13.

5. Bario RC, Agustin JA, Manzano MC, et al. In-Hospital Prognostic Value of Glomerular Filtration Rate in Patients With Acute Coronary Syndrome and a Normal Creatinine Level. Rev Esp Cardiol 2007; 60: 714-719.

6. National Kidney Foundation. Kidney Disease Outcome Quality Initiative (K/DOQI), Clinical practice guidelines for chronic kidney disease: evaluation, classification and stratification. Am J Kidney Dis 2002; 39: 1-266.

7. Stamatelopoulos KS, Lekakis JP, Tseke P, et al. Differential associations of renal function with coronary and peripheral atherosclerosis. Int J Cardiol 2009; 135(2): 162-164. 
8. Manjunath H, Tighiouart H, Ibrahim MB, et al. Level of kidney function as a risk factor for atherosclerotic cardiovascular outcomes in the community. $\mathrm{J} \mathrm{Am} \mathrm{Coll}$ Cardiol 2003; 41(1): 47-55.

9. Go SA, Chertow GM, Fan D, Hsu CY. Chronic kidney disease and the risks of death, cardiovascular events and hospitalization. New Engl J Med 2004; 351: 1296-1370.

10. Kiyosue A, Hirata Y, Ando J, et al. Relationship Between Renal Dysfunction and Severity of Coronary Artery Disease in Japanese Patients. Circulation 2010; 74: 478486.

11. Shulman NB, Ford CE, Hall WD, et al. Prognostic value of serum creatinine and effect of treatment of hypertension on renal function: results from the hypertension detection and follow-up program. The Hypertension Detection and Follow-up Program Cooperative Group, Hypertension 1989; 13(5): I80-193.

12. Chaitman BR, Bourassa MG, Davis K. Angiographic prevalence of high risk coronary artery disease in patients subsets. Circulation 1981; 64: 360-367.
13. Sullivan DR, Thomas H, Marwick S, Ben FD. A new method of scoring coronary angiograms to reflect extent of coronary atherosclerosis and improve correlation with major risk factors. Am Heart J 1990; 119: 1262-1267.

14. Gensini GG. A more meaningful scoring system for determining the severity of coronary heart disease. Am J Cardiol 1983; 51(3): 606.

15. Ozgirgin S, Ozmen D, Mutaf I, et a. Serum Carnitine Levels in Patients with Coronary Artery Disease. Turk $J$ Med Sci 2000; 30: 147-150.

16. Huang G, Zhao JL, Du H, Lan XB, Yin YH. Coronary Score Adds Prognostic Information for Patients With Acute Coronary Syndrome. Circulation 2010; 74(3): 490 - 495.

17. Montorsi P, Ravagnani PM, Galli S, et al. Association between erectile dysfunction and coronary artery disease. Role of coronary clinical presentation and extent of coronary vessels involvement: the COBRA trial. Eur Heart J 2006; 27: 2632-2639.

18. Cay S, Metin F, Korkmaz S. Association of renal functional impairment and the severity of coronary artery disease. Anadolu Kardiyol Derg 2007; 7: 44-48. 